\title{
Response Process of The Winter Soil Moisture of Different Vegetation Types to Rainfall Events in Karst Slope Land
}

Ershuang Yuan (D2515195146@qq.com )

Guizhou Normal University qiuwen zhou

Guizhou Normal University

weihong Yan

Guizhou Normal University

dawei peng

Guizhou Normal University

yalin wang

Guizhou Normal University

\section{Research Article}

Keywords: karst, winter, soil moisture, rainfall, vegetation

Posted Date: August 13th, 2021

DOl: https://doi.org/10.21203/rs.3.rs-794489/v1

License: (a) (i) This work is licensed under a Creative Commons Attribution 4.0 International License. Read Full License 
3 Ershuang Yuan ${ }^{\mathrm{a}}$, Qiuwen Zhou ${ }^{\mathrm{a}, \text { * }}$, Weihong Yan, Dawei Peng, Yalin Wang

\section{Rainfall Events in Karst Slope Land}

a School of Geography and Environmental Science, Guizhou Normal University, Guiyang 550025,

Guizhou, China; 2515195146@qq.com (E. Yuan); yanwh1210@163.com (W. Yan);

peng_dawei@163.com (D. Peng); 3514286848@qq.com(Y. Wang);

* Corresponding author at: School of Geography and Environmental Science, Guizhou Normal University, Guiyang 550025, Guizhou, China.

E-mall addresses: zouqiuwen@163.com (Q. zhou); Tel.: +86-851-8322-7361.

Abstract: Understanding the response process of the soil moisture of different vegetation types to rainfall in karst regions in winter is of great significance to the implementation of various ecological restoration projects. However, at present, the related research is mainly focused on nonwinter seasons, so there is less winter research. Therefore, in this study, in Guanling County, Anshun City, southwestern Guizhou Province, four types of vegetation, grassland, arable land, shrubland, and forestland, were selected as sample plots, and the degree、 time and speed responses of the soil moisture of the vegetation types to rainfall were calculated using the time series data of the soil moisture of different vegetation types. The results showed that among the four kinds of vegetation in karst regions in winter, the response degree of the grassland soil moisture to rainfall was largest, response duration was longest, and response speed was fastest. Also, the increment of the soil moisture in the adjacent

\section{Response Process of the Winter Soil Moisture of Different Vegetation Types to}


arable land soil layers significantly changed. In addition, in light rain events, only the soil moisture of the grassland and arable land responded. Overall, in this study, quantitative indices were used to illustrate the response process of soil moisture to rainfall for different vegetation types under the humid climate type of the mid-subtropical zone in pure limestone slope lands, thus enriching relevant knowledge systems and providing more scientific bases for the implementation of ecological restoration projects in karst areas.

Keywords: karst, winter, soil moisture, rainfall, vegetation

\section{Introduction}

Soil moisture, rainfall, and vegetation are interactive processes (Shuai et al., 2016; Daniele et al., 2008; Andrew et al., 2003; Eunhyung et al., 2019). On one hand, soil moisture affects the distribution of vegetation types (Zhao et al., 2019; Le er al., 2013). On the other hand, the vegetation type is considered to be the main factor controlling soil moisture (Yinglan et al., 2018; Chen et al., 2007). Among them, vegetation characteristics, such as irrigation, affect the redistribution of rainfall, thereby affecting the replenishment and change of soil moisture (Duan et al., 2016). Different vegetation types often have different characteristics of irrigation layers and may have different effects on soil moisture. Therefore, a clear understanding of the dynamic response process of soil moisture to rainfall for different vegetation types can help in understanding the hydrological process of soil moisture-vegetation-precipitation and may have scientific guiding significance for the 
implementation of various ecological restoration projects (Hou et al., 2018).

In recent years, more and more scholars have paid attention to studying the response process of the soil moisture of different vegetation types to rainfall. The results of their studies showed that in different periods, the response processes of the soil moisture of different vegetation types to rainfall are different. For example, Li et al. (2015) found that there are significant differences in the response patterns of soil moisture to rainfall in vegetable and forestland soils throughout the year. Also, Tian et al. (2019) found that in the vegetation growing season, the profile distribution patterns of the soil moisture response of shrubs and bare-land vegetation are similar, while the profile distribution patterns of meadows, high-coverage grasslands, and medium-coverage grasslands are significantly different. The above research results provide effective method references and valuable information for further research in non-karst areas, but the research rules may not be applicable to karst areas. The reason is that the properties of bedrock and soil are also important factors that affect the dynamic changes of soil moisture (Zhao and Gao, 2020). Compared with other areas, in karst areas, the bedrock is mostly carbonate rock, and karstification is strong, which makes the soil layer thin in such areas and leads to broken ground surfaces (Deng et al., 2020) and strong soil permeability. These characteristics may cause the degree, speed, and time of the soil moisture response to rainfall different from those in other regions. Thus, the response process of soil moisture to rainfall in karst regions differs from that in other regions.

Many scholars have studied the response process of the soil moisture of different 
vegetation types to rainfall in karst regions (Yang et al., 2019; Yolanda et al., 2016; Zhang et al., 2011; Fu et al., 2016). For example, Yang et al. (2021) found that under the same rainfall conditions, the response time of grassland soil moisture to rainfall is shorter than that of the soil moisture of farmland and bare land and that the sensitivity of soil moisture in grassland is higher than that in farmland and bare land. Zhou et al. (2019) found that with the increase in rainfall, the increase in the soil water content in forestland and shrubland is greater than that in bare land and grassland. These studies have also explained the response process of the soil moisture of different vegetation types to rainfall in terms of response degree and response time. However, the current studies on the response process of soil moisture to rainfall are mainly focused on nonwinter seasons (Chen et al., 2010; Guo et al., 2016), and there is not enough research for winter (Sun et al., 2020). Also, the changes in soil moisture in winter still form an important part of hydrological processes and affect vegetation restoration and ecological reconstruction. In the subtropical humid karst area, on one hand, winter vegetation transpiration is weak (Wang et al., 2021), the temperature is not too low, and a part of the vegetation is still growing. On the other hand, the seasonal distribution of rainfall is uneven (Xiao et al., 2021), there is little rain in winter, the leakage coefficient is large, and it is not easy for the surface to store water (Chen et al., 2021). The ability of soil to regulate water in dry seasons is more important.

Therefore, the response process of the soil moisture of different vegetation types to rainfall in winter is still an important investigation topic that needs to be accurately studied. 
Based on this, to find out the dynamic response process of the soil moisture of different vegetation types to rainfall events in winter, the response degree, response time, and response rate of the soil moisture of different vegetation types to rainfall in different soil layers were calculated, and the dynamic response process of soil moisture to rainfall was analyzed. Thus, the soil hydrological processes related to rainfall for different vegetation types in karst areas were revealed, and important reference values for the key management parameters of water resources were provided.

\section{Materials and methods}

\subsection{Study area}

The study area is located in the southwest of Guizhou Province, about $40 \mathrm{~km}$ southeast of Guanling County, Anshun City. The geographic coordinates are $105^{\circ} 43^{\prime} \mathrm{E}$, $25^{\circ} 44^{`} \mathrm{~N}$, and the altitude is $367 \sim 1831 \mathrm{~m}$. It belongs to the Wumeng Mountains and has large undulations. The types of landform in the territory are complex and diverse, the surface is broken, and limestone is widely distributed, which makes it a typical karst landform. The climate is humid mid-subtropical monsoon climate with an average annual temperature of $16.2^{\circ} \mathrm{C}$ and an annual precipitation of $1205.1 \sim 1656.8$ mm. The soil is mostly Rendzic Leptosols and brown Rendzic Leptosols. Natural vegetation mainly consists of forests, shrubs, grass, and other vegetation kinds. The forestland is mostly evergreen broad-leaved forest mixed with a small number of deciduous trees and cypress forests. Artificial vegetation is mainly composed of corn, 
plantain, emperor bamboo grass, and sugar cane.

109

110

111

112

113

114

115

\subsection{Sample plots design}

To eliminate the influence of the other environmental factors besides the vegetation types and related factors among the sample plots, all the selected sample plots were located on the same slope with an altitude of about $700 \mathrm{~m}$. The slope direction was NE, and the slope was about $25^{\circ}$. Due to the shallow soil layer of karst slope land, the sample plots selected in this study had a large amount of gravel that reached the bedrock ( $\sim 30 \mathrm{~cm}$ below the surface), and the soil thickness significantly varied. Therefore, the depth of the soil profile moisture observation was set to $20 \mathrm{~cm}$.

The main vegetation in this area is artificially planted corn and plantain in addition to secondary grasslands, shrubs, and forestland that have been naturally restored after the conversion of farmland. Four types of planting covers were chosen: arable land, secondary grassland, secondary shrubland, and secondary forestland, and monitoring plots were set up for them, respectively. The vegetation information and soil background of the sample plots are shown in Table 1, and Fig. 1 shows an overview of the sample plots and the distribution of their monitoring points.

Table 1 Overview of sample plots of various vegetation types

\begin{tabular}{lllllll}
\hline Vegetation & Vegetati & Vegeta & & & Soil bulk & Soil organic \\
Type of & on & tion & Soil type & & density & matter content \\
Plot & coverage & height & & & $(\mathrm{g} / \mathrm{cm})$ & $(\mathrm{g} / \mathrm{kg})$ \\
\hline arable & & & Rexture & & \\
land & $40 \%$ & $2 \mathrm{~m}$ & & & & \\
\end{tabular}




\begin{tabular}{|c|c|c|c|c|c|c|}
\hline \multirow{3}{*}{ Grassland } & \multirow{3}{*}{$70 \%$} & \multirow[b]{2}{*}{$0.7 \mathrm{~m}$} & Rendzic & Silty & \multirow{3}{*}{1.15} & \multirow{3}{*}{49.23} \\
\hline & & & & & & \\
\hline & & & Leptosols & loam & & \\
\hline \multirow{3}{*}{ Shrubland } & \multirow{3}{*}{$85 \%$} & \multirow{3}{*}{$3.4 \mathrm{~m}$} & Rendzic & Silty & \multirow{3}{*}{1.11} & \multirow{3}{*}{68.15} \\
\hline & & & & & & \\
\hline & & & Leptosols & loam & & \\
\hline \multirow{3}{*}{ Forestland } & \multirow{3}{*}{$95 \%$} & \multirow{3}{*}{$15 \mathrm{~m}$} & Rendzic & Silty & \multirow{3}{*}{1.04} & \multirow{3}{*}{70.90} \\
\hline & & & & & & \\
\hline & & & Leptosols & loam & & \\
\hline
\end{tabular}

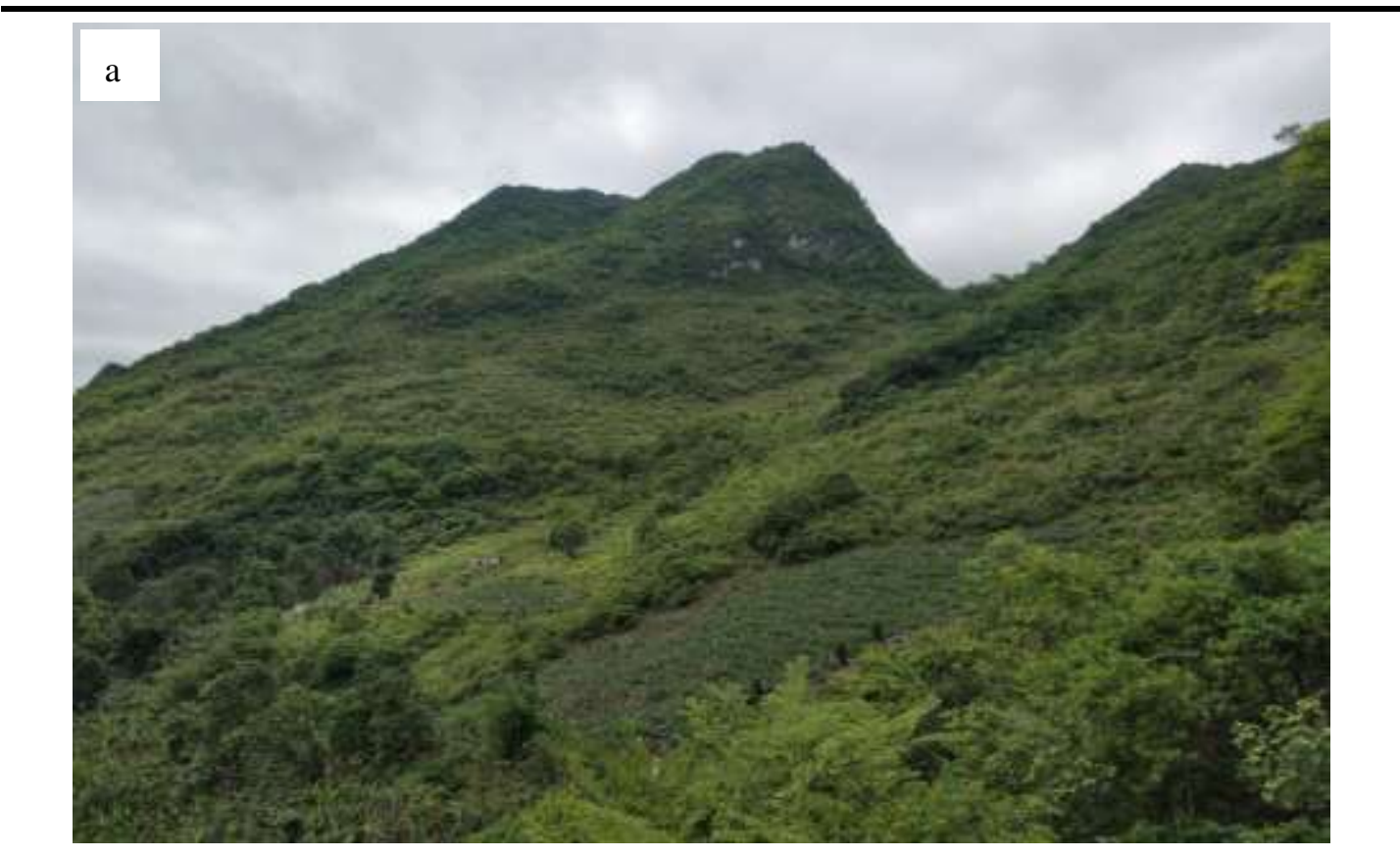

b

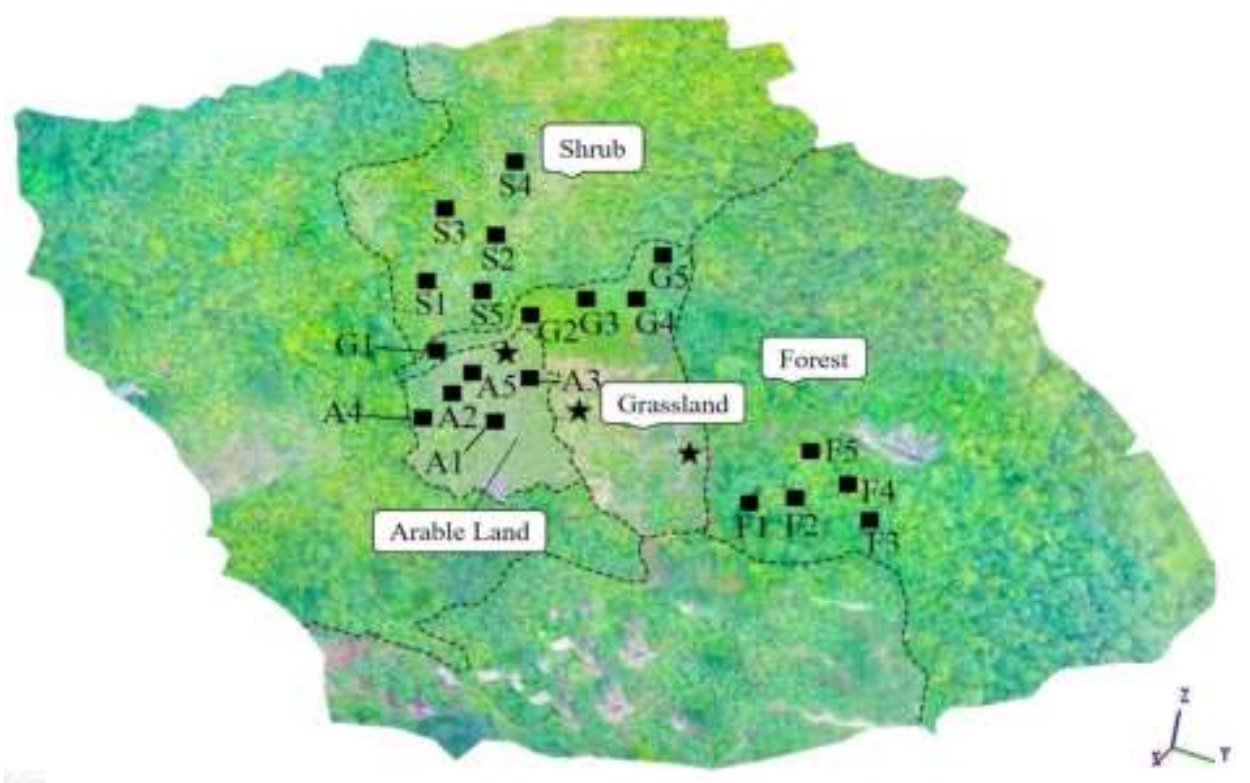


Fig 1. Overview map of the sample plots (a) and distribution map of the monitoring points (b). In Figure 1b, A1, A2, A3, A4, and A5 are arable land monitoring points, G1, G2, G3, G4, and G5 are grassland monitoring points, F1, F2, F3, F4, and F5 are forest land monitoring points, and $\mathrm{S} 1, \mathrm{~S} 2, \mathrm{~S} 3, \mathrm{~S} 4$, and $\mathrm{S} 5$ are shrubland monitoring points. The dotted line separates the different vegetations from each other. represents the automatic rainfall thermometer.

\subsection{Observation data collection}

For each vegetation type, 5 monitoring points with a size of $5 \mathrm{~m} \times 5 \mathrm{~m}$, an interval of about $20 \mathrm{~m}$, and 4 sample plots were randomly selected (a total of 20 monitoring points). The HOBO H21_USB soil moisture monitoring system was used at each monitoring point, and the ECH2O-5 probe (The METER Group, Inc. USA) was horizontally inserted in the soil layers at different depths (first layer: $0-5 \mathrm{~cm}$; second layer: $5-10 \mathrm{~cm}$; third layer: $10-15 \mathrm{~cm}$; fourth layer: $15-20 \mathrm{~cm})$. Real-time monitoring of the soil moisture changes during rainfall was performed, the data collection frequency was 10 minutes, and the monitoring time was from July 5, 2019 to January 2020 6th. Taking into account the actual start and end of winter in the study area, the soil moisture data for this study were selected from November 5, 2019 to January 6, 2020.

The HOBO RG3_M automatic recording rainfall thermometer observation map was used for the rainfall data. Concerning the monitoring points of each vegetation type, two monitoring points were selected to place this type of rainfall thermometer on the forest surface to observe the penetrating rainfall in the forest and the near-surface temperature under the vegetation. The data collection frequency was 10 minutes, and it was synchronized with the soil moisture data. The rainfall observation 
152

153

154

155

156

157

158

159

160

161

162

163

164

165

172

period was from November 5, 2019 to January 6, 2020.

\subsection{Experimental methods}

In each plot, soil samples were collected at 4 layers $(5 \mathrm{~cm}, 10 \mathrm{~cm}, 15 \mathrm{~cm}, 20 \mathrm{~cm})$

to determine the soil properties. A 100- $\mathrm{cm}^{3}$ ring knife was used (bottom surface: 20

$\mathrm{cm}^{2}$; height: $5 \mathrm{~cm}$ ) to collect undisturbed soil from the 4 soil layers of each sample

plot to determine the bulk density, total porosity, capillary porosity, noncapillary

porosity, and saturated hydraulic conductivity. The sampling time was July 5-21,

2019. The experimental procedure is as follows. Soak the ring knife with the

undisturbed soil in water until the weight becomes stable, and weigh $W_{s}(\mathrm{~g})$ when the

soil becomes saturated. Then, put the ring knife on the ring knife holder, add an empty ring knife to each ring knife and seal it, add water to the upper edge of the empty ring

knife and maintain the water level, collect the water seepage using a triangular flask

and a funnel, and record the amount of water conduction $h\left(\mathrm{~cm}^{3}\right)$ corresponding to

time $t(\mathrm{~h})$. After the recording is complete, place the ring knife in the ring knife holder and do not add more water until the gravity water is excluded, where the weight is $W_{g}$

(g). Transfer the soil discharged from the gravity water to an aluminum box with a

weight of $W_{b}(\mathrm{~g})$, weigh the empty ring knife weight $\mathrm{Wr}(\mathrm{g})$, and set the oven at $105^{\circ} \mathrm{C}$ to dry the aluminum box with the soil sample for about 8 hours until the weight becomes stable. Then, weigh $W_{d}(\mathrm{~g})$ The calculation method of each soil attribute is shown by formulas (1-4).

The calculation method of the soil bulk density $B D\left(\mathrm{~g} / \mathrm{cm}^{3}\right)$ is as follows: 
$173 \quad B D=\frac{W_{d}-W_{b}}{100}$.

174 In the formula, 100 is the undisturbed soil volume $\left(\mathrm{cm}^{3}\right)$.

175 The calculation method of the porosity $T P(\%)$ is as follows:

$176 T P=\frac{\left(W_{s}-W_{r}\right)-\left(W_{d}-W_{b}\right)}{100} \times 100$.

177 In the formula, the first 100 is the undisturbed soil volume $\left(\mathrm{cm}^{3}\right)$, and the second 100

178 is the percentage conversion coefficient.

179 The calculation method of the saturated hydraulic conductivity $S H(\mathrm{~cm} / \mathrm{h})$ is as

180 follows:

$181 \quad S H=\frac{h}{t \times 20}$.

182

183

184

185

186

187

188

189

190

191

192

The organic matter content was determined using the potassium dichromate

titration method. Under heating conditions, a certain amount of potassium dichromate solution was used to oxidize the organic carbon in the soil with the participation of concentrated sulfuric acid, and the remaining potassium dichromate was titrated with ferrous sulfate. The amount of organic carbon was calculated from the amount of the consumed potassium dichromate. Then, it was converted to the soil organic matter content. According to the soil organic matter content of the experimental plots, the weight of each soil sample used in the experiment was $0.15 \mathrm{~g}$, and the oven was heated at $185-190^{\circ} \mathrm{C}$ for 15 minutes. The calculation method of the organic matter content $O C(\mathrm{~g} / \mathrm{kg})$ is as follows:

$$
O C=\frac{\left(V_{0}-V\right) \times C \times 1 / 6 \times 3 / 2 \times 0.012 \times 1.724 \times 1.08}{S_{d}} \times 1000
$$


where $V_{0}(\mathrm{ml})$ is the consumption of the ferrous sulfate solution in the blank test,

$V(\mathrm{ml})$ is the consumption of the ferrous sulfate solution when the test liquid is titrated,

$C(\mathrm{~mol} / \mathrm{L})$ is the molar concentration of the $\mathrm{FeSO}_{4}$ standard solution, $0.012(\mathrm{~g})$ is the

weight of 1 millimole of carbon, $1.724(\mathrm{~g})$ is the organic matter weight in grams

(equivalent to $1 \mathrm{~g}$ of carbon and calculated based on the average soil organic matter

carbon content of 58\%), 1.08 is the correction factor ( $~ 90 \%$ oxidation), $1 / 6$ is the

molecular ratio of potassium dichromate and ferrous sulfate, $3 / 2$ is the molar ratio of

potassium dichromate and carbon, and 1000 is the unit conversion factor.

Determination of the soil mechanical composition: The soil mechanical

composition was measured using a laser particle size analyzer, and the international

203

According to the international system, The map of the corresponding soil triangle

206

quality determines the type of soil texture. When conducting the soil mechanical

207

composition experiment, apretreatment was performed after removing the calcium

208

carbonate and organic matter, and a dispersant was added and then left to stand for 24

209

hours before using the machine.

210

The soil bulk density, soil porosity, saturated hydraulic conductivity, soil particle

size, and organic matter content are important factors that affect the dynamic changes

of soil moisture. In this study, they were used as auxiliary factors to explain the

dynamic changes of soil moisture for different vegetation types. 


\subsection{Data analysis}

There were a total of 20 monitoring points for the 4 sample plots, where there were 5 monitoring points for each sample plot. Each monitoring point was divided into 4 soil layers for monitoring. A total of 80 soil moisture probes were used to obtain time series soil moisture data through probe monitoring. The average of the soil moisture time series of each soil layer of each vegetation type at the 5 monitoring points was calculated as the soil moisture time series of the soil layer of the vegetation type. During each rainfall, soil moisture presents a dynamic change process that first increases and then decreases, where it usually increases after rainfall and then decreases. Therefore, the data of the rainfall impact period was intercepted 10 minutes before the beginning of rainfall to 12 hours after the end of rainfall for the rainfall study. Change characteristics of soil moisture at time (the interval before and after the rainfall record is within 12 hours is regarded as the same rainfall).

There were a total of 20 monitoring points, 4 soil layers, and 80 soil samples with the determination results of the soil properties. The average value of the measurement results of the 20 soil samples at the 5 monitoring points and the 4 soil layers of each vegetation type was calculated as the soil properties of the vegetation type. Also, the average value of the soil properties of the soil samples at the 5 monitoring points for each vegetation type and each soil layer was calculated as the soil layer properties of the vegetation type. 


\subsection{Identification of soil moisture in response to rainfall events}

Usually, after rainfall, it can be assumed that the rainfall infiltration has reached a certain soil profile layer when its soil moisture starts to increase (Wang et al., 2008;

Lozano et al., 2015; Laio et al., 2001). Therefore, in this study, we used the increase in soil moisture in each layer after rainfall to describe the soil moisture response process of the profile after rainfall. For this reason, we intercepted 10 minutes before the beginning of rainfall to 12 hours after the end of rainfall as the rainfall impact period data. Also, we identified all the processes of soil moisture during this period as follows: beginning to increase, increasing and stopping, starting to decrease, and stopping to decrease. as the soil moisture response process. The response of moisture to rainfall events.

By taking into account the accuracy of the soil moisture probe, a rainfall event with an increase in soil moisture of more than $0.2 \%$ (Lin et al., 2008) was considered an effective rainfall event. There were 14 rainfalls in the observation period (the periods before and after the rainfall records within 12 hours were regarded as the same rainfall). According to the standards of the National Meteorological Administration of China, the rainfall intensity during the experiment period was divided, and the number of rainfall events of each type was counted. Finally, the rainfall was divided into light rain events and moderate rain events, of which a total of 12 rain events occurred in light rain events and 2 rain events occurred in moderate rain events. 
Quantifying the response process of soil moisture can provide reference indicators for process-based soil hydrological processes (Green et al., 2011; Clark et al., 2017). Therefore, in this study, we used a series of quantitative indicators to characterize the response process of soil moisture so as to quantitatively describe the dynamic response process of soil moisture to rainfall events under different vegetation types. this study, the absolute cumulative increase in soil moisture during rainfall events, ASWI was used as the response degree of soil moisture to rainfall. The formula is as follows:

$$
A S W I^{j}=\sum_{t=S T}^{E T} \Delta \theta_{t+}^{j}
$$

Where

$$
\Delta \theta_{t^{+}}^{j}\left\{\begin{array}{l}
\Delta \theta_{t}^{j}, \Delta \theta>0 \\
0, \Delta \theta_{t}^{j} \leq 0
\end{array}\right\}
$$

$\Theta_{\mathrm{t}}^{\mathrm{j}}$ is the soil moisture at a time $\mathrm{t}$ in the $j$ th soil response event, $\Delta t$ is the time interval (10 min), ST and ET denote the start and end time of the $j$ th soil response event, and $A S W I$ is the cumulative soil moisture increase of the soil response event. 
273

274

275

$$
S_{\text {mean }}=\operatorname{mean}\left(100 \times \frac{\theta_{t+\Delta t}-\theta_{t}}{\Delta t}\right)
$$

$$
S_{\max }=\max \left(100 \times \frac{\theta_{t+\Delta t}-\theta_{t}}{\Delta_{t}}\right)
$$


the soil response event). The soil moisture response time difference between adjacent soil layers is used to describe the migration process of the soil response peak, and it can be calculated by formula (10):

$$
D R T=S T_{i}-S T_{i-1}
$$

$$
\text { layers to rainfall events, respectively, and } D R T \text { is the response time difference. The }
$$

soil response event duration is calculated according to formula (11):

$$
\text { Duration }_{j}=E T_{\mathrm{j}}-S T_{\mathrm{j}}
$$

Among them, $E T_{j}$ and $S T_{j}$ are the start and stop times of the $j$ th soil response event, respectively.

\section{Results}

\subsection{Dynamic changes of the soil moisture and rainfall in the monitoring period}

As shown in Fig. 2, the dynamic changes of the soil moisture in the different vegetation types in the monitoring period changed based on the rainfall changes, and there were differences in the soil moisture changes in each soil layer. With the increase in rainfall, the soil moisture of various vegetation types significantly fluctuated. Among them, the grassland soil moisture significantly fluctuated with the change in rainfall, and the soil moisture of each soil layer of the shrub had obvious differences. 

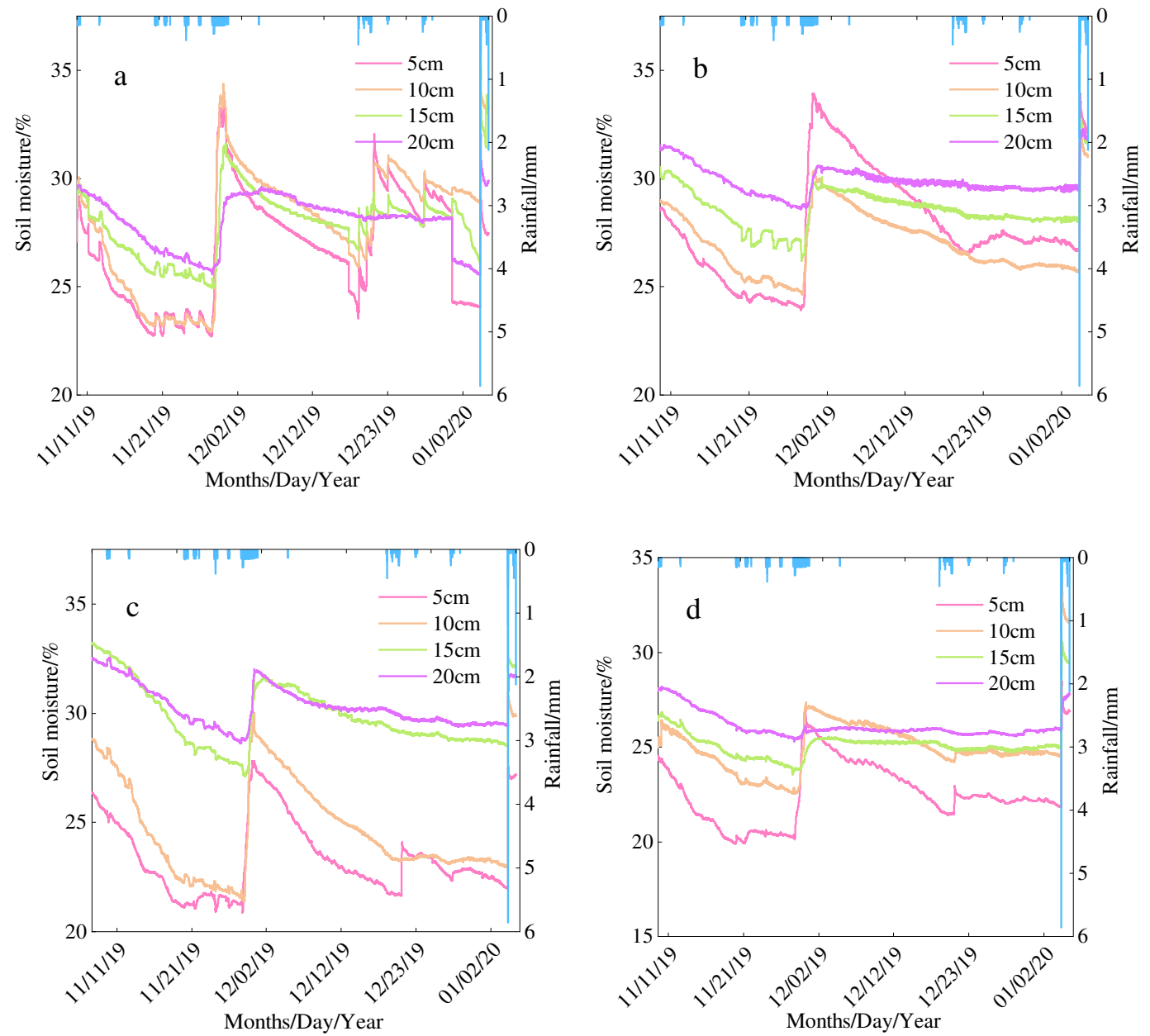

Fig 2. Distribution diagram of soil moisture and rainfall time series of different vegetation types during the monitoring period. a: grassland, b: represents arable land, c: shrubland, d: forestland .

\subsection{Response degree of the soil moisture of different vegetation types to different}

\section{rainfall events}

It can be seen from Figs. 3 and 4 that under light rain conditions, the $A S W I$ of the soil moisture of each vegetation type decreased with the increase in depth. In the case of moderate rain, the $A S W I$ of the grassland and arable land reached the highest level

319 in the second layer and then decreased with the increase in depth. Also, the ASWI of

320 the shrub and forestland decreased with the increase in depth. In addition, the RSWI was below $100 \%$, indicating that the soil moisture response to rainfall events 
generally decreased with the increase in soil depth, and the response of the adjacent soil layers to soil moisture The degree weakens along with the profile.

As shown in Figs. $3 \mathrm{a}$ and 4a, the ASWI of the grassland under moderate rain conditions was greater than that under light rain conditions. The response depth of the grassland soil moisture to light rain was only $15 \mathrm{~cm}$, and the response depth to moderate rain was $20 \mathrm{~cm}$. This shows that the response degree of grassland soil moisture to rainfall increases with the increase in rainfall. As shown in Figs. $3 b$ and 4b, the RSWI was below $100 \%$ under light rain conditions and was below $100 \%$ under moderate rain conditions except for the second layer (103.93\%). This shows that the overall change trends of the soil moisture in the adjacent soil layers of grassland are basically similar. By comparing the $A S W I$ and $R S W I$ of grassland under different rainfall events, the response degree of the grassland soil moisture to moderate rain was greater than that to light rain. Compared with other vegetation types, grassland has the highest $A S W I$ value, indicating that grassland soil moisture has the greatest response to rainfall.

The $A S W I$ of the arable land under moderate rain conditions was significantly greater than that under light rain conditions. The ASWI of the arable land under light rain conditions decreased with the increase in soil depth. Also, the ASWI of the arable land under moderate rain conditions was highest in the second layer and then gradually decreased. The depth of the soil moisture response of the cultivated land to light rain was only $10 \mathrm{~cm}$, while it was $20 \mathrm{~cm}$ in the case of moderate rain. Except for the moderate rain conditions, the second layer (222.50\%) of the arable land $R S W I$ was 
344

greater than $100 \%$, and the values of the other soil layers were all less than $100 \%$.

This shows that the response degree of the arable land soil moisture to moderate rain events is greater than that in the case of light rain events. In addition, compared with other vegetation types, the $R S W I$ value of each layer of the arable land significantly varied.

The soil moisture of the shrubland and forestland did not respond to light rain events. Under moderate rain events, the $A S W I$ of the shrubland and forestland was maximum in the first layer, and the $R S W I$ was below $100 \%$. This shows that the response of the soil moisture of shrubland and forestland to rainfall decreased with the increase in the soil layer.

Under light rain events, the response degree of the soil moisture of the grassland and farmland decreased with the increase in the soil layer. Under moderate rain events, the response degree of the soil moisture of the grassland and arable land was maximum in the second layer, and the response degree of the soil moisture of the shrubland and forestland was maximum in the first layer. In general, the responses of grassland and arable land to rainfall are similar in distribution along with the profile, and shrub and forest land are similar.
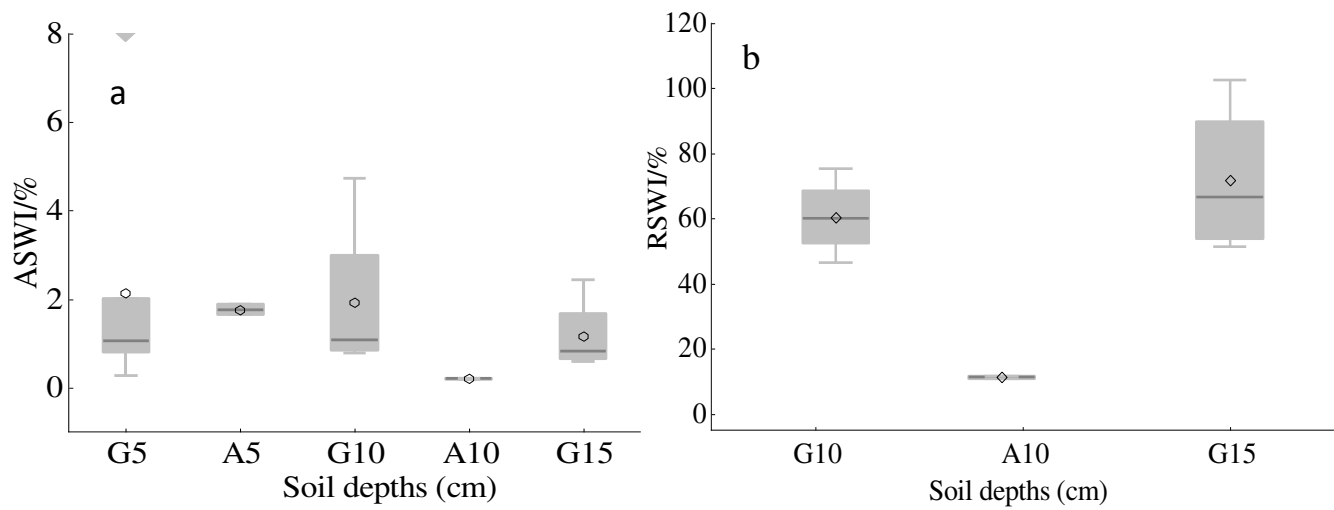
362

363

364

365

366

Figure 3. ASWI (a) and RSWI (b) distribution diagrams of different vegetation types under light rain events. In the box diagram, $G$ represents grassland and A represents arable land.
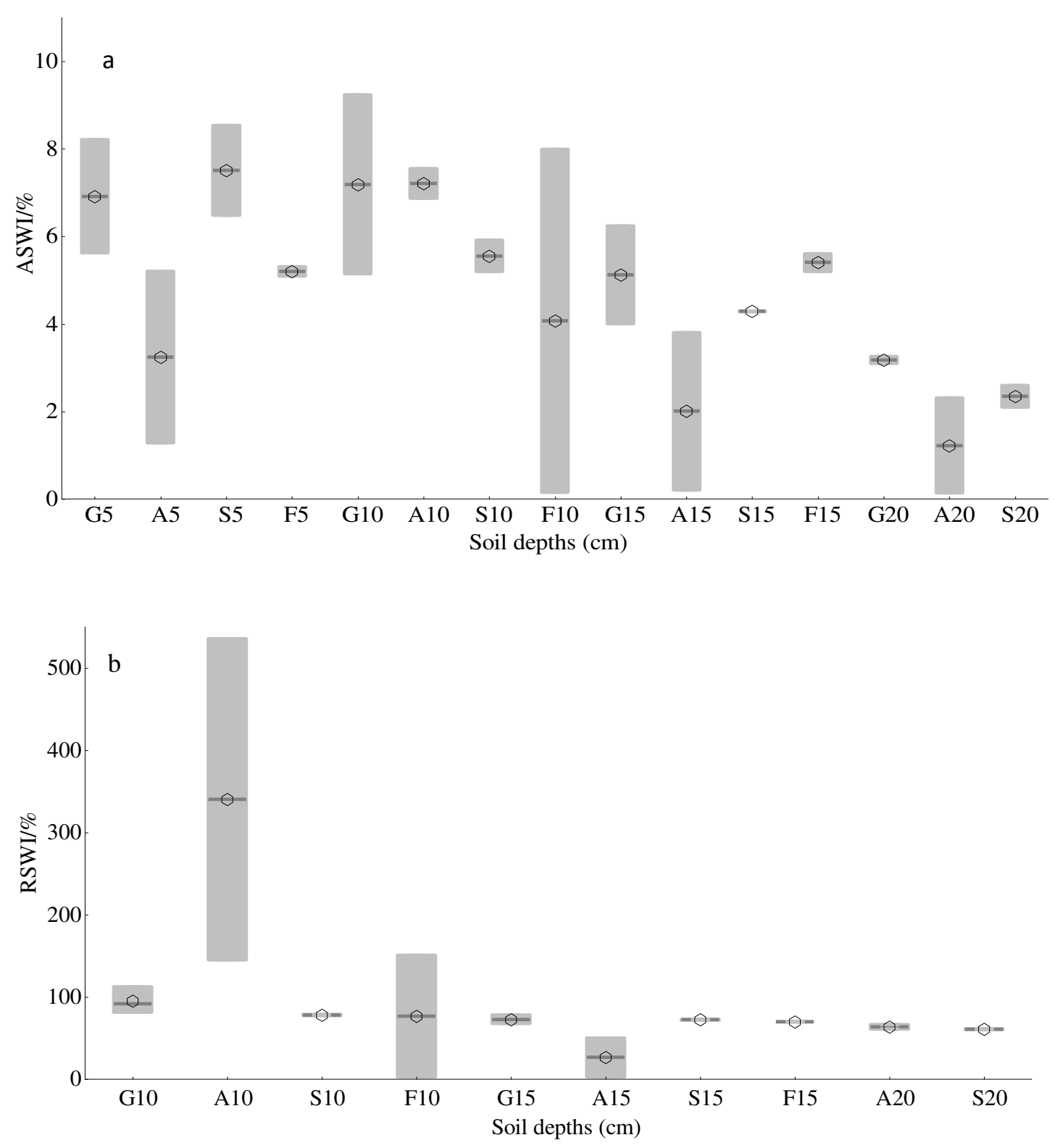

Fig 4. ASWI (a) and RSWI (b) distribution map of different vegetation types under moderate rain events. In the Fig 4, G stands for grassland, A stands for arable land, S stands for shrubland, and $\mathrm{F}$ stands for forestland.

3.3 Response time of the soil moisture of different vegetation types to different rainfall events

As shown in Fig. 5a, under a light rain event, the difference in the soil moisture 
response time $(D R T)$ between the adjacent grassland soil layers increased with the increase in the soil layer, and the maximum $D R T$ value appeared in the third grassland layer. As shown in Fig. 6a, under a moderate rain event, the $D R T$ of the different vegetation types increased in the following order: forestland $<$ shrubland $<$ grassland < arable land. Except for grassland, the $D R T$ values of the other vegetation types all increased with the increase in the soil layer, showing that the soil moisture response speed of the adjacent soil layers continued to decrease as rainfall infiltrated into the deep soil layers.

As shown in Fig. 5b, under a light rain event, the soil moisture response duration (Duration) of the grassland and arable land slightly changed in the same soil layer, and the maximum value of Duration appeared in the third grassland layer. As shown in Fig. 6b, under a moderate rain event, the duration of each vegetation type significantly varied in different soil layers, from 0.23 hours to 54 hours. Compared with the other vegetation types, the Duration of each grassland soil layer was highest, and the Duration in the case of moderate rain was significantly greater than that in the case of light rain. Change from 13.08 hours to 54.98 hours. The duration of arable land and shrubland increased from 0.23 hours to 21.80 hours, and it also increased from 9.67 hours to 33.00 hours with the increase in depth. The duration of the forestland changed from 5.33 hours to 34.95 hours.

The above analysis shows that in the case of light rain, the grassland soil moisture response lasted longer than that of the arable land. Compared with the other vegetation types, in the case of moderate rain, the grassland soil moisture response 
layers of the shrubland was minimum.

397

398

399

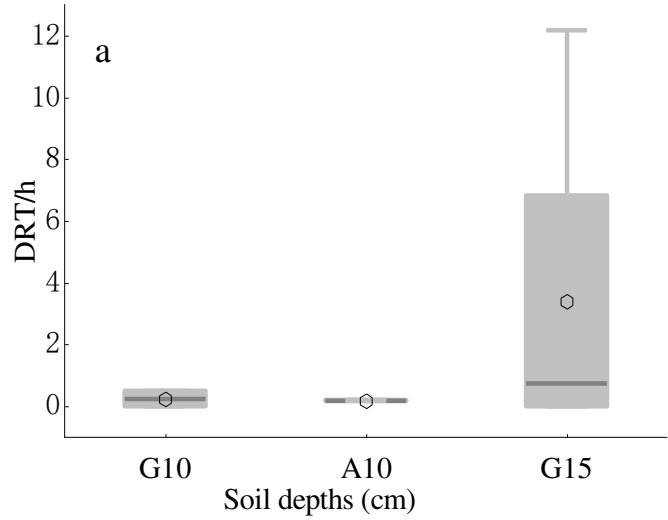

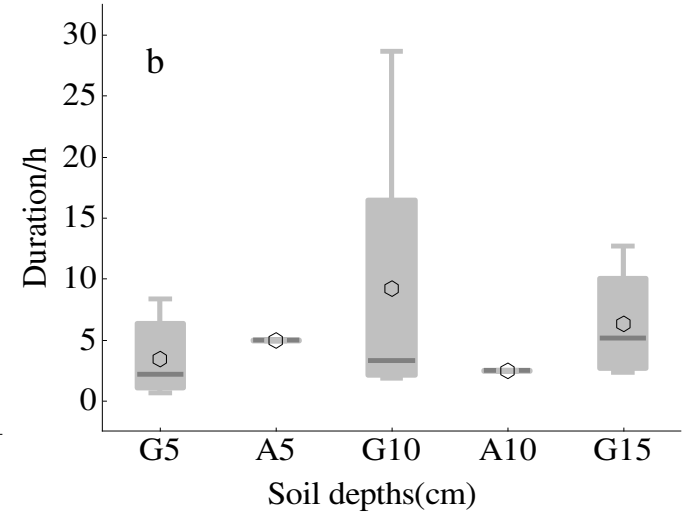

Fig 5. DRT (a) and Duration (b) distribution maps of different vegetation types under light rain events. In the Fig., G represents grassland and A represents arable land.

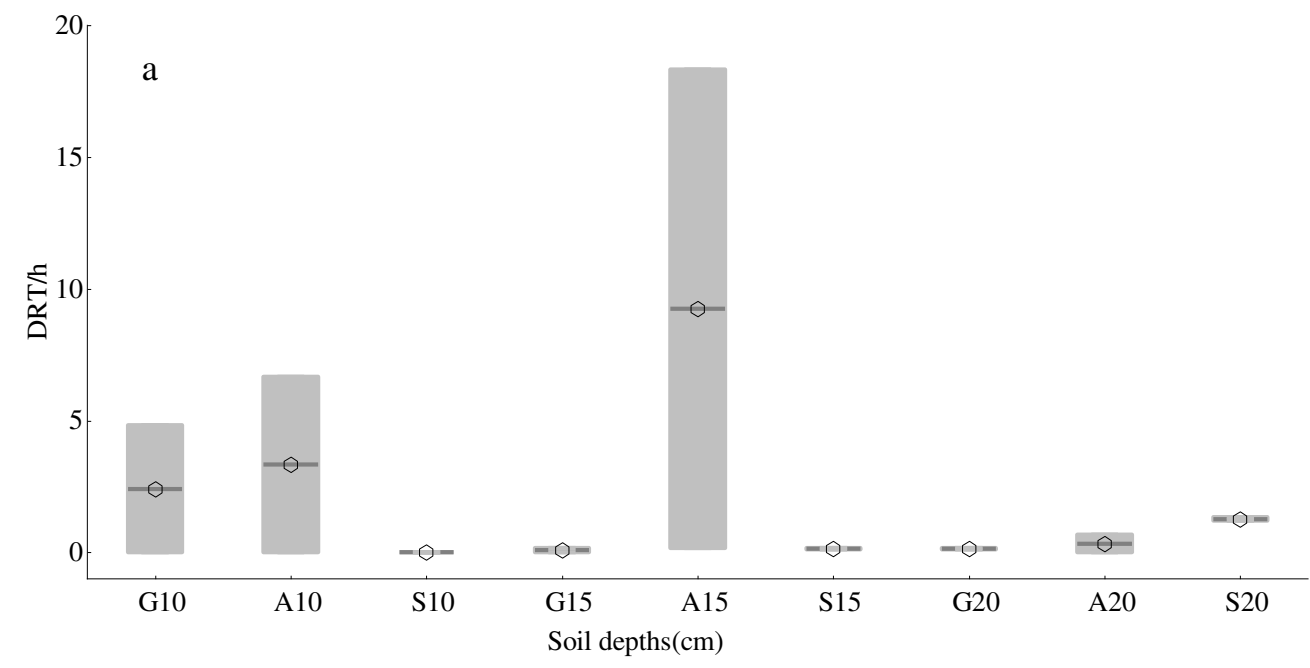

400

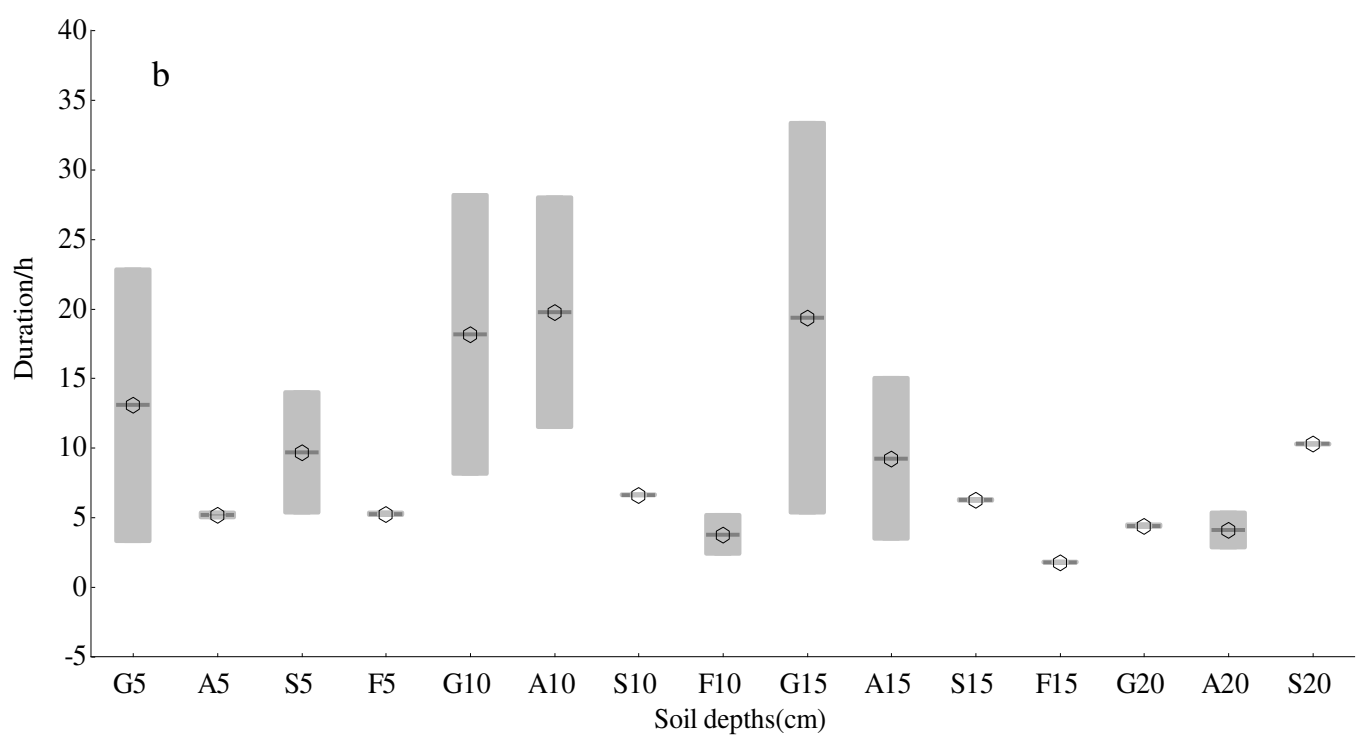


402

403

404

405

406

407

408

409

410

411

412

413

Fig 6. DRT (a) and Duration (b) distribution maps of different vegetation types under moderate rain events. In the Figure, G stands for grassland, A stands for arable land, S stands for shrubland, and $\mathrm{F}$ stands for forestland.

\subsection{Response speed of the soil moisture of different vegetation types to different}

\section{rainfall events}

It can be seen from Figs. 7 and 8 that in the case of light rain, the $S_{\text {max }}$ and $S_{\text {mean }}$ of the grassland and arable land decreased with the increase in the soil layer, and the response speed of the grassland was significantly higher than that of the arable land, where the response speed was fastest in the first layer. This shows that the response speed of the soil moisture of various vegetation types under light rain events decreases with the increase in the soil layer. In the case of moderate rain, the response speeds of the soil moistures of different vegetation types were different, but the highest values of $S_{\max }$ and $S_{\text {mean }}$ appeared in the first grassland layer.

As shown in Fig. 7, in the case of light rain, the $S_{\max }$ and $S_{\text {mean }}$ of the grassland and arable land decreased with the increase in the soil layer, and $S_{\max }$ was highest (1.62 vol.\%/min) in the first layer. As shown in Fig. 8, in the case of moderate rain, the $S_{\max }$ and $S_{\text {mean }}$ of the first grassland layer and the farmland soil moisture were much higher than those of the other soil layers, indicating that the soil moisture response speed was fastest in this layer. In the case of moderate rain, the $S_{\max }$ and $S_{\text {mean }}$ of the shrubs both decreased with the increase in the soil layer. The $S_{\max }$ of the forestland increased and the $S_{\text {mean }}$ decreased with the increase in the soil layer. In general, the response speed of the soil moisture of all vegetation types was fastest in the first layer. The response speed of the soil moisture in the case of moderate rain 

vegetation types.
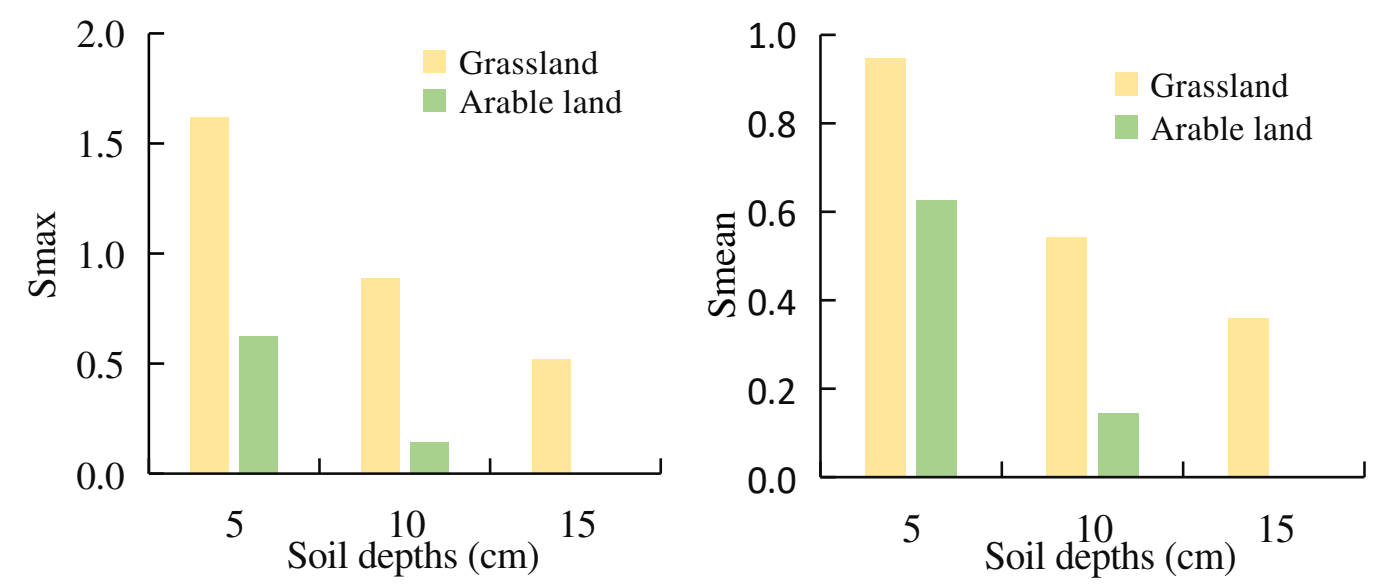

Fig 7. Soil response rate of different vegetation types under light rain event (Smax and Smean)
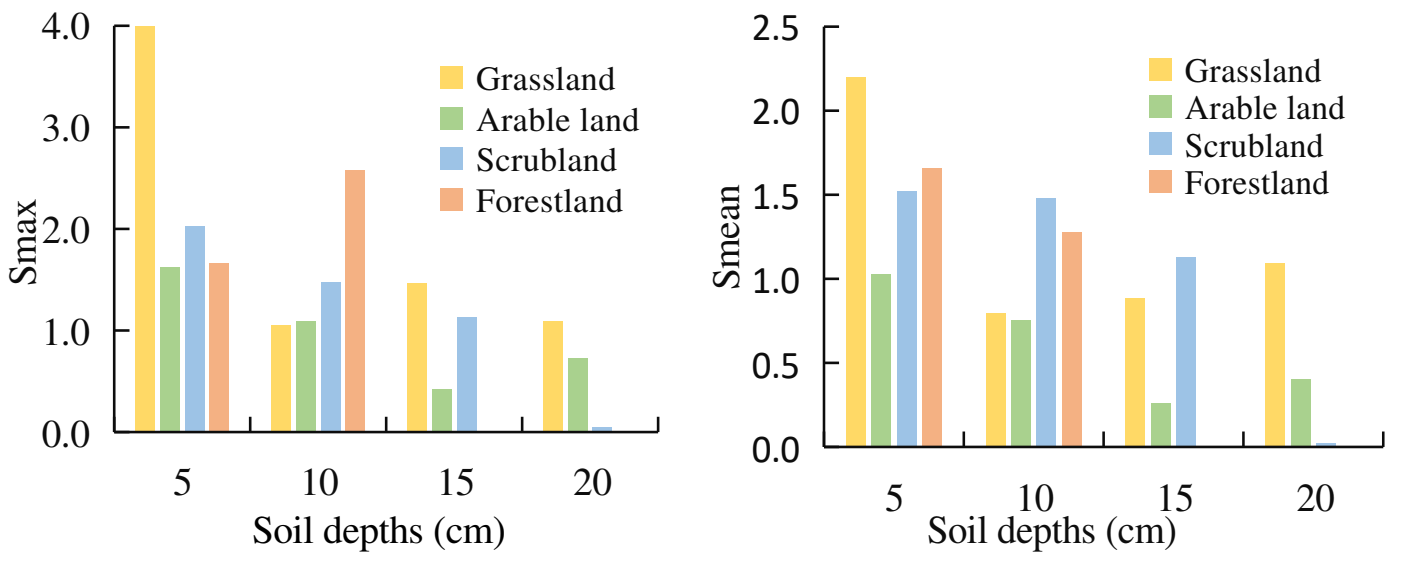

430

Fig 8. Soil response rates of different vegetation types under moderate rain events (Smax and Smean)

\section{Discussion}

\subsection{Response process of the winter soil moisture of different vegetation types in}

\section{karst areas}

Through this study, it was found that compared with other vegetation types, karst slopes in grassland have the largest response to rainfall, the longest response duration, 
and the fastest response speed in winter. These results are different from the nonwinter research results of Yang Zhigang et al. (2021) in karst areas. Thus, the response processes of the soil moisture of different vegetation types to rainfall in karst areas in winter and in nonwinter seasons are different. The reason may be the seasonal difference in different vegetation types (Duan et al., 2016). For example, compared with forestland and shrubland, grassland in winter has less litter and low vegetation coverage. Compared with winter grassland, arable land has a relatively high vegetation coverage and a relatively large rainfall interception due to its winter dry crops. Therefore, compared with other vegetation types, the indicators of the grassland soil moisture response to rainfall in winter are larger than those of other vegetation types. In addition, in winter karst environments, compared with other vegetation types, the grassland vegetation coverage is low and the interception is relatively small. In addition, karst rock fissures are currently being developed (Li et al., 2020). After rainfall, most of the surface runoff quickly enters the ground along with rock fissures, resulting in faster and longer responses to rainfall in winter grassland.

Fig. 2 shows that only the soil moisture of the arable land and grassland responded in the case of light rain. This may be due to the differences in the physical properties of soil (Peng et al., 2020). First, the saturated hydraulic conductivity, noncapillary porosity, and organic matter content of the shrubland and forestland were greater than those of the arable land and grassland (Fig. 8), indicating that the water holding capacity of shrubland and forestland is relatively poor. In addition, in the 
463 forestland, the grassland and arable land in the winter had relatively small interception the arable land was greater than $100 \%$, indicating that the cumulative increase in the soil moisture of the arable land was maximum in the second layer. This $\quad d \quad \jmath$
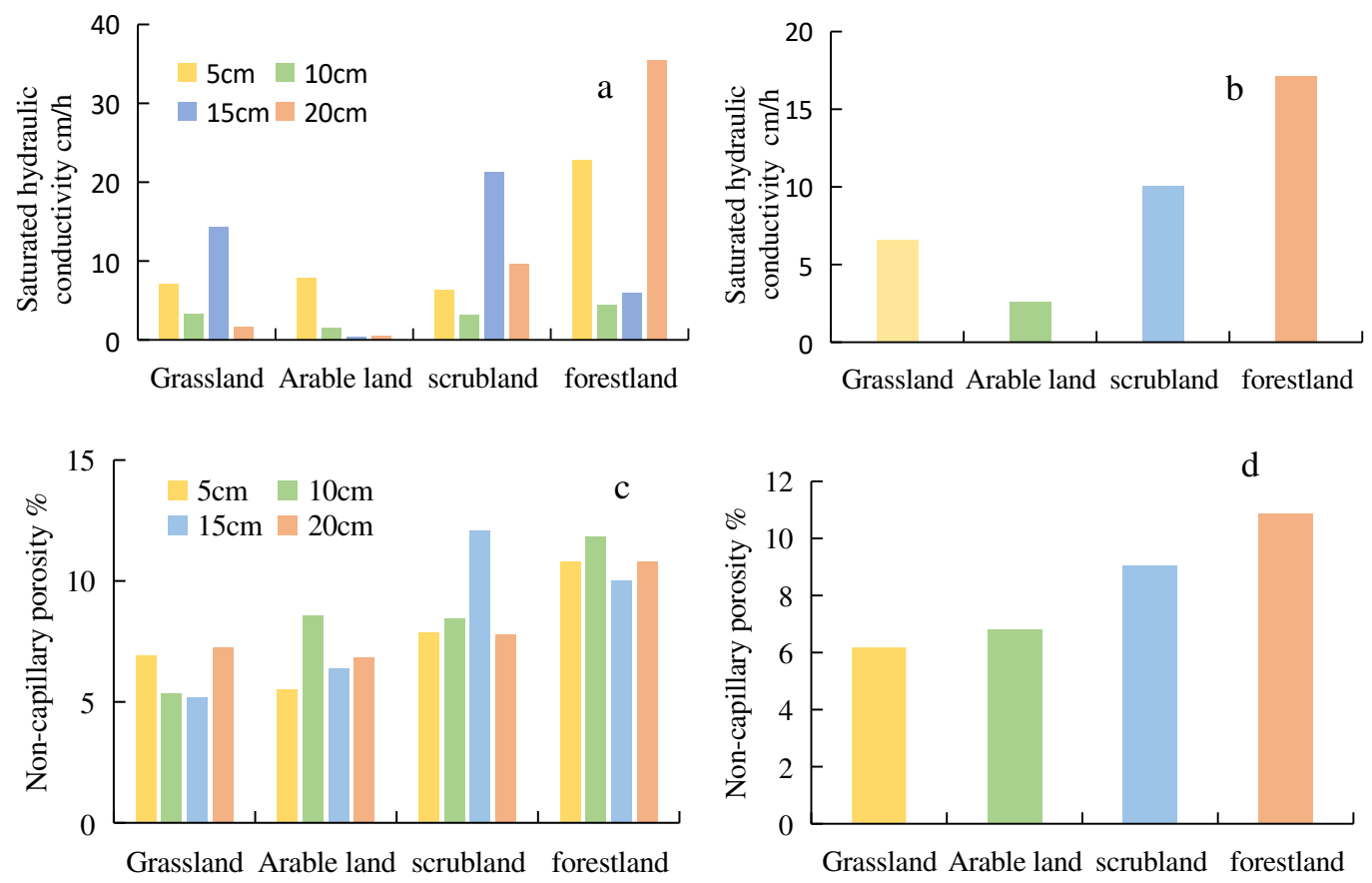

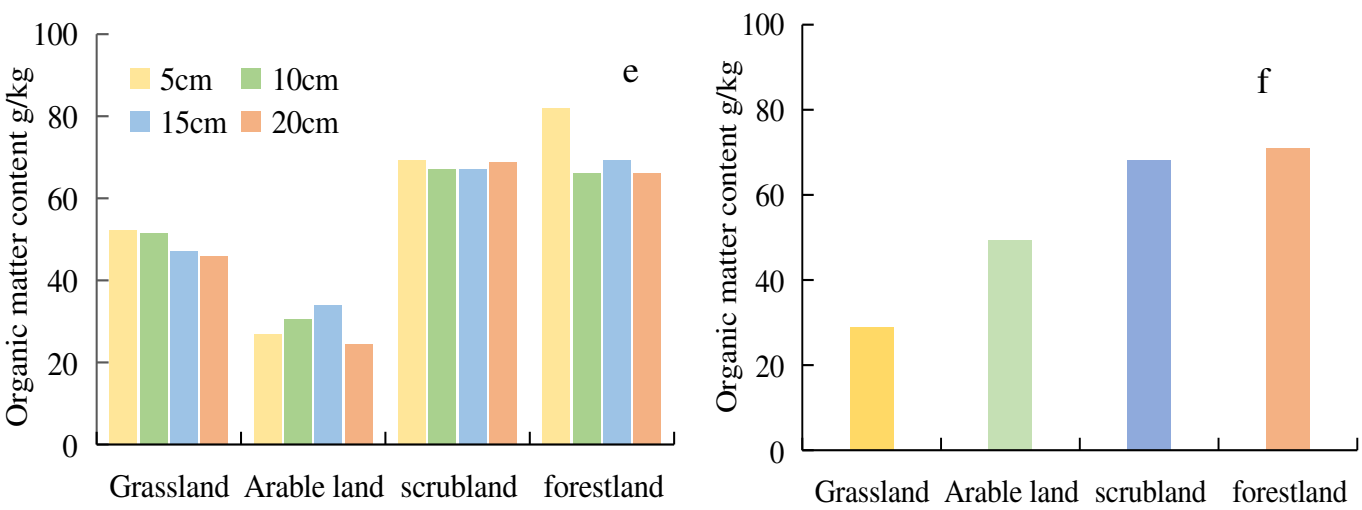

475

476

477

478

479

480

481

482

483

484

485

486

487

Fig 9. Soil properties of different vegetation types. a: saturated hydraulic conductivity, b: average profile saturated hydraulic conductivity, c: noncapillary porosity, d: average profile noncapillary porosity.

\subsection{Karst environment impact on the research results}

The geological background of karst areas is complex. Even if they are all carbonate rocks, the parent rock formed by the soil is different, and the soil bulk density, soil pore water, capillary water holding capacity, and other soil properties are different (Sheng et al., 2018). For example, the Rendzic Leptosols formed by calcareous dolomite is compared with the Rendzic Leptosols formed by pure limestone, which has strong water permeability, small water holding capacity, and low natural water content (Huang et al., 1988). These differences in soil properties lead to differences in the response process of the soil moisture of different vegetation types during rainfall. The used sample plots in this study are located on a pure limestone slope, which only represents the response process of the soil moisture of different vegetation types to rainfall on a pure limestone slope.

Second, karst areas have great spatial heterogeneity. Even if the bedrock is the same, the vegetation and seasonal characteristics of different climate types are 
493

494

495

different, which may cause differences in the response process of soil moisture to rainfall (Chen et al., 2009). For example, in the same limestone karst area, in the case of humid mid-subtropical climate, the vegetation seasonal differences are more obvious. In summer, the vegetation is dark green, and the canopy closure is relatively large. In autumn, yellow-brown patches appear, and in winter, most of the leaves fall, leaving only dry branches. In the semi-humid climate of South Asia, although vegetation significantly differs from summer to winter, only some dominant species are deciduous in winter, and the forest layer is complex, where there are abundant plants in the middle forest layers, and the winding density of rattan (Huang et al., 1988). These different vegetation characteristics may cause the interception of winter vegetation of this climate type to be greater than that of the mid-subtropical humid climate type, which may lead to differences in the response process of winter vegetation soil moisture to rainfall (Chen et al., 2010). This study area belongs to the humid mid-subtropical climate, which only represents the response process of different vegetation soil moistures to rainfall in this climate type, while the response process of vegetation soil moisture to rainfall in other climate types needs further investigation.

To sum up, this study can better explain the response process of soil moisture to rainfall in winter for different vegetation types in the mid-subtropical humid climate of pure limestone slope land. The results of this study have enriched the understanding of the response process of the soil moisture of different vegetation types to rainfall in karst slopes and supplemented this knowledge system. This study 
also showed certain reference values for understanding the hydrological process of soil moisture-vegetation-precipitation and implementing various ecological restoration projects.

\section{Conclusion}

In this study, to explain the response process of the soil moisture of four vegetation types to rainfall in karst areas in winter, the response degree, response time, and response speed of the soil moisture of different vegetation types to rainfall were calculated using the time series data of the soil moisture of different vegetation types. The results showed that for grassland soil moisture, the response degree, response duration, and response speed to rainfall are largest, longest, and fastest, respectively. Also, the increment of the soil moisture in the adjacent soil layer of the arable land significantly changed among the four vegetation types of the selected karst slope land in winter. In addition, in the case of light rain, only the soil moistures of the grassland and arable land showed responses. Overall, the findings of this study supplement the understanding of the soil moisture of different vegetation types in karst slope land with regard to the rainfall response process and enrich the related knowledge system. However, whether the response process of soil water to rainfall in winter under other conditions, such as different bedrocks, climate types, vegetation types, and karst areas, will have new characteristics is a further question that needs more investigation.

\section{Declaration of Competing Interest}

The authors declare that they have no known competing financial interests or personal relationships that could have appeared to influence the work reported in this 
paper.

\section{Acknowledgements}

This work was supported by the Joint Fund of the National Natural Science

Foundation of China and the Karst Science Research Center of Guizhou province

[grant number U1812401]; the National Science Foundation of China [grant number

41761003]; the Scientific and Technological Research Project of Guizhou Province

[grant number Qiankehe Jichu [2019]1433 \& Qiankehe Pingtai Rencai [2017]5726];

the Foundation Programme for Outstanding Talents in Higher Education Institutions

of Guizhou Province [grant number [2018]042].

\section{References}

Andrew, W.W., Sen-Lin, Z., Rodger, B.G., Thomas, A.M., Günter, B., David, J.W., 2003. Spatial correlation of soil moisture in small catchments and its relationship to dominant spatial hydrological processes. J. Hydrol. 286(1), 113-134. https://doi.org/10.1016/j.jhydrol.2003.09.014.

Chen, H.S., Zhang W.,Wang K.L., Fu,W., 2010. Soil moisture dynamics under different land uses on karst hillslope in northwest Guangxi, China. Environ.Earth Sci. 61(6), 1105-1111. https://doi.org/10.1007/s12665-009-0428-3.

Chen, H.S., Mingan, S., Yuyuan L., 2007. Soil desiccation in the Loess Plateau of China. Geoderma. 143(1-2), 91-100. https://doi.org/10.1016/j.geoderma.2007.10.013.

Clark, M.P., Bierkens, M.F.P., Samaniego, L., Woods, R.A., Uijlenhoet, R., Bennett, K.E., Pauwels Valentijn, R.N., Cai ,X.T., Wood Andrew, W., Peters-Lidard, C.D., 2017. The evolution of process-based hydrologic models: historical challenges and the collective quest for physical realism. Hydrol. Earth Syst. Sci. 21(7), 3427-3440. https://doi.org/10.5194/hess-21-3427-2017.

Chen, X., Zhang, Z.C., Chen, X.H., Shi, P., 2009. The impact of land use and land cover changes on soil moisture and hydraulic conductivity along the karst hillslopes of southwest China. Environ. Earth Sci. 59(4),811-820. https://doi.org/10.1007/s12665-009-0077-6.

Daniele, P., Marco, B., Daniele, N., Giancarlo, D.F., 2008. Hillslope scale soil moisture variability in a steep alpine terrain. J. Hydrol. 364(3), 311-327. https://doi.org/10.1016/j.jhydrol.2008.11.009.

Duan, L.X., Huang, M.B., Zhang, L.d., 2016. Differences in hydrological responses for different vegetation types on a steep slope on the Loess Plateau, China. J. Hydrol. 537, 356-366. https://doi.org/10.1016/j.jhydrol.2016.03.057.

Deng, Y.H., Wang, S.J., Bai, X.Y., Luo, G.J., Wu L.H., Chen, F., Wang, J.F., Li Q., Li, C.J., Yang, 
Y.J., Hu, Z.Y., Tian, S.Q., 2020. Spatiotemporal dynamics of soil moisture in the karst areas of China based on reanalysis and observations data. J. Hydrol. 585, 124744. https://doi.org/10.1016/j.jhydrol.2020.124744.

Eunhyung, L., Sanghyun, K., 2019. Wavelet analysis of soil moisture measurements for hillslope hydrological processes. J. Hydrol., 575, 82-93. https://doi.org/10.1016/j.jhydrol.2019.05.023. Chen, F., Wang, S.J., Bai, X.Y., Liu, F., Zhou, D.Q., Tian, Y.C., Luo, G.G., Li, Q., Wu, L.H., Zheng, C., Xiao, J.Y., Qian, Q.H., Cao, Y., Li, H.W., Wang, M.M., Yang, Y.Y., 2021. Assessing spatial-temporal evolution processes and driving forces of karst rocky desertification. Geocarto Int. 36(3),1-22. https://doi.org/10.1080/10106049.2019.1595175.

Fu, T.G., Chen, H.G., Fu, Z.Y., Kelin, W., 2016. Surface soil water content and its controlling factors in a small karst catchment. Environ.Earth Sci. 75(21),1406. https://doi.org/10.1007/s12665-016-6222-0.

Green, T.R., Erskine, R.H., 2011. Measurement and inference of profile soil-water dynamics at different hillslope positions in a semiarid agricultural watershed. Water Resour. Res. 47(12), 366-378. https://doi.org/10.1029/2010WR010074.

Gao, J.B., Zuo, L.Y., Liu, W.l., 2020. Environmental determinants impacting the spatial heterogeneity of karst ecosystem services in Southwest China. Land degrad. Development. 32(4), 1718-1731. https://doi.org/10.1002/LDR.3815.

Guo, X.X., Gong, X.P., Tang, Q.J., Chen, C.J., Jiang, G.H., Li, X., Zou, Y., 2016. Research on the Response Process of Soil Moisture in Typical Karst Hillside to Rainfall. China Karst. 35(06), 629-638.(In Chinese)

Hou, G.R., Bi, H.X., Wei, X., Kong, L.X., Wang, N., Zhou, Q.Z., 2018. Response of Soil Moisture to Single-Rainfall Events under Three Vegetation Types in the Gully Region of the Loess Plateau. Sustainability. 10(10),1-17. https://doi.org/10.3390/su10103793.

Huang, W.1., Vegetation in Guizhou. 1988. Guizhou People's Publishing House .

Wiekenkamp, I., Huisman, J.A., Bogena, H.R., Lin, H.S., Vereecken, H., 2016. Spatial and temporal occurrence of preferential flow in a forested headwater catchment. J. Hydrol. 534:139-149. https://doi.org/10.1016/j.jhydrol.2015.12.050.

Li, S.,Wei, L., Fu, B.J., Lü, Y.H., Fu, S.Y., Wang, S., Su, H.M., 2016. Vegetation changes in recent large-scale ecological restoration projects and subsequent impact on water resources in China's Loess Plateau. Sci.of the total. Environt. 569, 1032-1039. https://doi.org/10.1016/j.scitotenv.2016.06.141.

Le, R.P.C., Aalto, J., Luoto, M., 2013. Soil moisture's underestimated role in climate change impact modelling in low-energy systems. Glob. Change Biol. 19(10), 2965-2975. https://doi.org/10.1111/gcb.12286.

LI, Q., Zhu, Q., Zheng, J.S., Liao, K.H., Yang, G.S., 2015. Soil Moisture Response to Rainfall in Forestland and Vegetable Plot in Taihu Lake Basin,China. Chin. Geographical Sci. 25(04),426-437. https://doi.org/10.1007/s11769-014-0715-0.

Lozano-Parra, J., Schnabel, S., Ceballos-Barbancho, A., 2015. The role of vegetation covers on soilwetting processes a rainfall event scale in scattered tree forestland of Mediterranean climate.J. Hydrol. 529, 951-961. https://doi.org/10.1016/j.jhydrol.2015.09.018.

Laio, F., Porporato, A., Fernandez-Illescas, C.P., Rodriguez-Iturbe, I., 2001. Plants in water-controlled ecosystems: active role inhydrologic processes and response to water stress : II. Probabilistic soil moisture dynamics. Advances in Water Resour. 2001, 24(7):695-705. 
https://doi.org/10.1016/S0309-1708(01)00007-0.

Lin, H., Zhou, X., 2008. Evidence of subsurface preferential flow using soil hydrologic monitoring in the Shale catchment. Eur. J. Soil Sci. 59, 34-49. https://doi.org/10.1111/j.1365-2389.2007.00988.x.

Li, Y., Liu, Z., Liu, G.,2020. Dynamic variations in soil moisture in an epikarst fissure in the karst rocky desertification area. J. Hydrol. 591(7), 125587. https://doi.org/10.1016/j.jhydrol.2020.125587.

McColl, K.A., Alemohammad, S.H., Akbar, R., Konings, A.G., Yueh, S., Entekhabi, D., 2017. The global distribution and dynamics of surface soil moisture. Nat. Geosci. 10(2), 100-104. https://doi.org/10.1038/ngeo2868.

Sheng, M.Y., Xiong, K.G., Wang, L.G., Li, X.N., Li, R., Tian, X.J., 2018. Response of soil physical and chemical properties to Rocky desertification succession in South China Karst. Carbonates and Evaporites. 33(1), 15-28. https://doi.org/10.1007/s13146-016-0295-4.

Peng, X.D., Dai, Q.H., Ding, G.J., Shi, D.M., Li, C.J., 2020. Impact of vegetation restoration on soil properties in near-surface fissures located in karst rocky desertification regions. Soil Tillage Res. 200, 104620. https://doi.org/10.1016/j.still.2020.104620.

Sun, Z.Y.,2020. Research on the Soil Moisture Effect and Influencing Factors of Vegetation Restoration in Karst Sloping Land. Guizhou Normal University.(In Chinese)

Sun, F.X., Lü, Y.H., Wang, J.L., Hu, J., Fu, B.J., 2015. Soil moisture dynamics of typical ecosystems in response to precipitation: a monitoring-based analysis of hydrological service in the Qilian Mountains. Catena 129 (1), 63-75. https://doi.org/10.1016/j.catena.2015.03.001.

Tian, J., Zhang, B.Q., He, C.S., Han, Z.B., Bogena, H.R., Huisman, J.A., 2019. Dynamic response patterns of profile soil moisture wetting events under different land covers in the Mountainous area of the Heihe River Watershed, Northwest China. Agric. and For. Meteorology. 271, 225-239. https://doi.org/10.1016/j.agrformet.2019.03.006.

Wang, M., Ding, Z., Wu, C.Y., Song, L.S., Ma, M.G., Yu, P.J., Lu, B.Q., Tang, X.G., 2020. Divergent responses of ecosystem water-use efficiency to extreme seasonal droughts in Southwest China. Sci. of the Total Environ.760, 143427. https://doi.org/10.1016/J.SCITOTENV.2020.143427.

Wang, T.J., Zlotnik, V.A., Wedin, D., Wally, K.D., 2008. Spatial trends in saturated hydraulic conductivityof vegetated dunes in the Nebraska Sand Hills: Effects of depth and topography. Jourmnal ofHydrology. 349(1-2), 88-97. https://doi.org/10.1016/j.jhydrol.2007.10.027.

Xiao, W.J., Yan, Y., Jiang, X.G., He, Z,L., Zou, X.G., You, X.H., Yang, Y.Y., Zeng, Z.Z., Shi, W.Y., 2021. Different responses of ecohydrological processes in the re-vegetation area between the dip and anti-dip slope in a karst rocky desertification area in southwestern China. Plant and Soil. 1-19. https://doi.org/10.1007/s11104-020-04821-9.

Yinglan, A., Wang, G.Q., Sun, W.C., Xue, B.L., Kiem, A., 2018. Stratification response of soil water content during rainfall events under different rainfall patterns. Hydrol.Process. 32(20), 3128-3139. https://doi.org/10.1002/hyp.13250.

Yang, J., Chen, H.S., Nie, Y.P., Wang, K.L., 2019. Dynamic variations in profile soil water on karst hillslopes in Southwest China. Catena. 172, 655-663. https://doi.org/10.1016/j.catena.2018.09.032.

Yolanda, C., Rodríguez-Caballero, E., Contreras, S., Villagarcia, L., Li, X.Y., Solé-Benet, A., Domingo, F., 2016. Vertical and lateral soil moisture patterns on a Mediterranean karst 
hillslope. J. of Hydrol. and Hydromech. 64(3),209-217.

https://doi.org/10.1515/johh-2016-0030.

Yang, Z.C., Ke, Q.H., Ma, Q.H., Cao, Z.H., Zhang, K.L., 2021. Response of Soil Moisture on Yellow Soil Slope in Karst Area to Rainfall. J. of Soil and Water Conservation. 35(02),75-79. (In Chinese)

Zhao, Y.L., Wang, Y.Q., Wang, L., Zhang, X.Y., Yu, Y.L., Zhao, J., Lin, H., Chen,Y.P., Zhou, W.J., An, Z.S., 2019. Exploring the role of land restoration in the spatial patterns of deep soil water at watershed scales. Catena. 172, 387-396. https://doi.org/10.1016/j.catena.2018.09.004.

Zhao, Z.M., Shen, Y.X., Wang, Q.G., Jiang, R.H., 2020. The temporal stability of soil moisture spatial pattern and its influencing factors in rocky environments. Catena.187:,104418. https://doi.org/10.1016/j.catena.2019.104418.

Zhang, J.G., Chen, H.S., Su, Y.R., Shi, Y., Zhang, W., Kong, X.L.,2011. Spatial Variability of Surface Soil Moisture in a Depression Area of Karst Region. Clean-Soil Air Water. 39 (7), 619-625. https://doi.org/10.1002/clen.201000528.

Zhou, Q.W., Sun Z.R., Liu, X.L., Wei, X.C., Peng, Z., Yue, C.W., Luo, Y.X., 2019. Temporal Soil Moisture Variations in Different Vegetation Cover Types in Karst Areas of Southwest China: A Plot Scale Case Study. Water. 11(7),1423. https://doi.org/10.3390/w11071423. 